\title{
Geoecological aspects of technogenic impact on the territory of raw materials production for construction
}

\author{
Andrey Lavrusevich ${ }^{1}$, Alisa Abene ${ }^{1}$, and Ivan Lavrusevich ${ }^{1, *}$ \\ ${ }^{1}$ Moscow State University of Civil Engineering, Yaroslavskoe sh. 26, 129337 Moscow, Russia
}

\begin{abstract}
The article is devoted to the problem of inconsistency of needs of the modern stage of the life activity of human society and the possibilities of self-restoration of Earth's geospheres. The increase in the technogenic load and the rate of consumption of natural resources leads to a disturbance of the natural balance. On the example of territories of mining of nonmetallic materials, it is shown how technogenic transformation of the natural environment provokes extensive negative consequences. As a result of the quarrying of non-metallic raw materials for the construction industry, the relief, microclimate, hydrological and hydrogeological regimes of the territories, the state of ecosystems, and the pollution of the environment are changing. In the vast territories of the deposits themselves and areas adjacent to them, dangerous exogenous geodynamic processes (suffosion, erosion, landslides, screes, etc.) develop. To preserve the natural balance, it is necessary to conduct comprehensive monitoring in the areas of deposits and introduce a system of recultivation measures.
\end{abstract}

\section{Introduction}

In modern conditions, due to the growth of population and steady increase in consumption of natural resources, there is a rapid development of science, technologies and the equipment. The question of optimization of interaction of the nature and society becomes more and more relevant [1].

The mankind expands areas of dwelling by building megalopolises with skyscrapers of height exceeding 800 meters and going deep into Earth subsoil by means of mines and wells for production of energy and raw material resources.

Constantly growing requirements of human society determine emergence of more and more effective technical means and technologies for development of raw fields. However, an increase in the rates of an expenditure and production of resources, which is inconsistent with the possibilities of self-restoration of Earth's geospheres, leads to violation of natural balance. By the beginning of the 21 st century, influence of a technogenesis has reached the menacing scales, and a danger of death of all life on Earth became obvious to a considerable part of the population (see fig. 1).

* Corresponding author: 4914907@gmail.com 


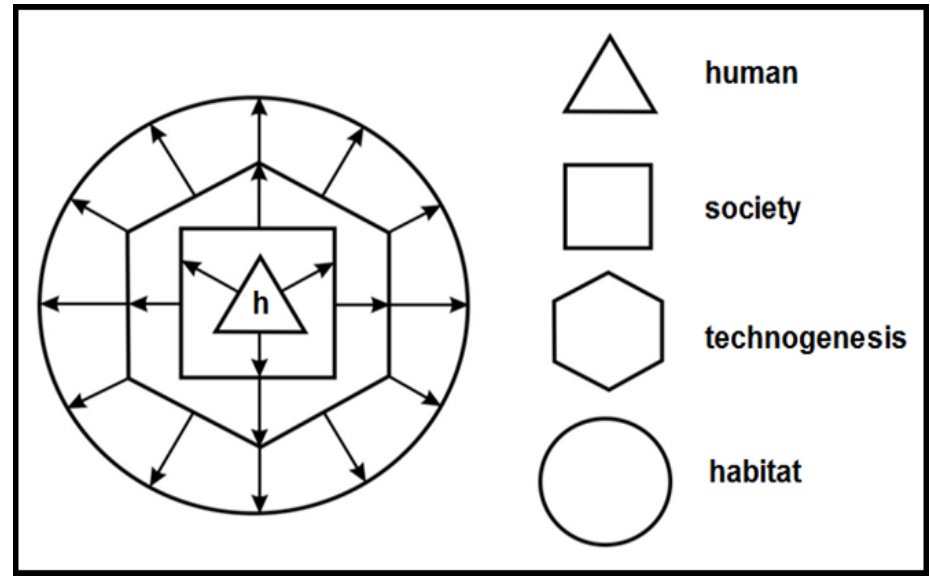

Fig. 1. Scheme of the impact of a technically armed society on the environment.

Technogenesis as «a process of change of natural complexes and biogeocenoses as a result of production activity of the human» [1] is an area of research of geoecology. N. F. Reymers considered geoecology as the section of ecology which is investigating geosystems of various hierarchical levels. This integral science of ecological orientation allows studying regularities of functioning of technogenesis that changes ecosystems of various levels of the organization, taking into account all sets of their interrelations [2]. One of the widely used building materials is cement. This building material has been used by mankind since ancient times, and, nevertheless, it was the widespread use of cement that activated the processes of technogenesis [3].

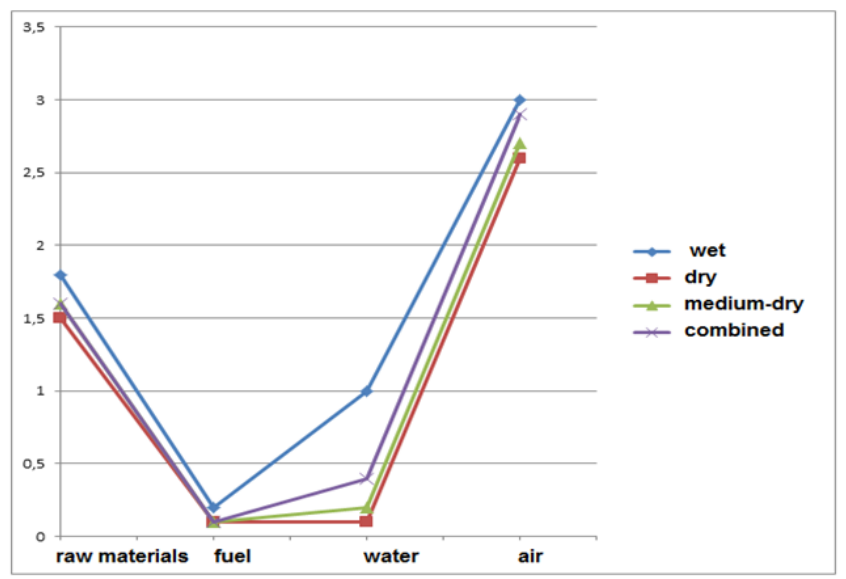

Fig. 2. Consumption of resources in the production of cement clinker in various ways.

The technological process of cement production is associated with a multi-stage mechanical and high-temperature processing of raw materials and is characterized by high consumption of fuel and mineral resources (See Figure 2). In addition, it is accompanied by the formation of different (depending on the mode of production), but invariably significant amount of pollutants and emissions into the atmosphere (see Figure 3) $[4,5,6]$. The impact of the cement industry covers the entire technological chain: from raw materials and primary processing, through the production processes for baking and grinding, to transportation, the use of the final product and the disposal of production waste. The harmful emissions of 
cement industry enterprises change the geochemical background in the vast areas adjacent to the plants $[3,4,7]$.

The main types of raw materials used for the production of cement clinker are calcareous, marly and clayey rocks, which are usually mined in open quarries. The choice of the method of extraction depends on the geomorphological conditions of the terrain and the physical and chemical properties of the extracted raw materials [4].

However, the construction industry, with all the variety of materials used in it, is not limited to the use of cement. Concrete and its derivatives are almost the most popular and used material for all types of modern construction. Concrete, in addition to cement, includes aggregates such as sand and crushed stone. To increase the physical and operational characteristics of concrete, reinforcement (reinforced concrete) is used, as well as various plasticizers, etc.

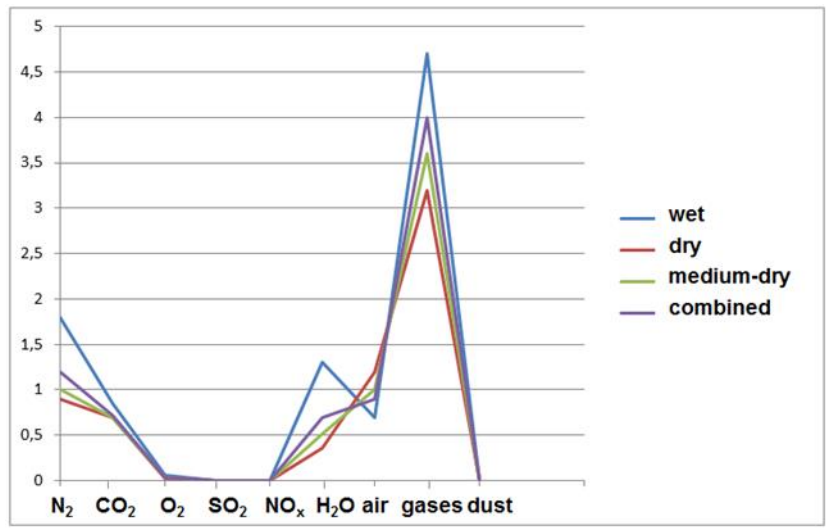

Fig. 3. Gas-dust emissions in the production of cement clinker in various ways.

Many nonmetallic minerals, such as sand, clays, limestone, chalk and others, are extracted in quarries and delivered to production. Extraction of raw materials is carried out by means of the mining and pit operations including such main operations as drilling, blast operations, excavation, crushing, and transportation $[3,4,5]$. Territories of mining of non-metallic materials where blasting operations are organized are hazardous production facilities and are classified by hazard level.

When excavating natural mineral raw materials, a serious technogenic load on all components of the environment occurs (see Fig. 4). As a result of this influence, the relief, microclimate, the hydrological and hydrogeological modes, flora and fauna change. There is a pollution of the environment. First of all, the accumulation of large volumes of overburden and containing breeds, the high level of dust formation, noise, vibration, emissions of pollutants, etc, are distinguished as the problems arising at the extraction of raw materials [4, 7]. Due to the excavation, the movement of considerable volumes of breeds and the creation of dumps reaching 100 meters or more and which are quite often placed on fertile sites, the natural relief is replaced by technogenic.

On the territory of extraction, as a result of violation of integrity of the massif and excavation of considerable volumes of breed, there is a violation of its structural durability, increase in permeability and working cycles. The changing of the hydrogeological mode and degree of dispersion of breed creates prerequisites for development of erosive, suffosion and post-suffosion processes. As a result of the development of suffosion processes, there are changes of particle size distribution of breeds because of the increasing of their porosity and permeability. Structural connections are weakened and collapsed in them, the channels and cavities are formed. Superficial manifestations of the suffosion can have accumulative and 
destructive character. The suffosion is one of the geodynamic processes leading to essential transformations of natural and natural-technogenic systems [8].

On the edges of the quarries made from carbonate clays and massifs of loess loams, the pseudo-karst phenomena also develop (funnels, sinkholes, bowls, etc.) $[8,9]$.

The development of erosive processes in territories of the developed fields is connected, first of all, with the movement of the water streams containing rain, thawed or underground waters. Planar erosion has a detrimental effect on the soil, washing away the required amount of soil cover and leads to loss of soil fertility as a result of holding the main layer of humus. The process of linear washout of rocks of temporary waterways leads to formation of ravines, gullies and furrows. Along with an atmospheric precipitation, the lack of specially organized systems of a superficial drain, water disposal and dumping, and also enough vegetation on slopes which constrains the development of this geodynamic process promote the development of erosion in the territory of quarries.

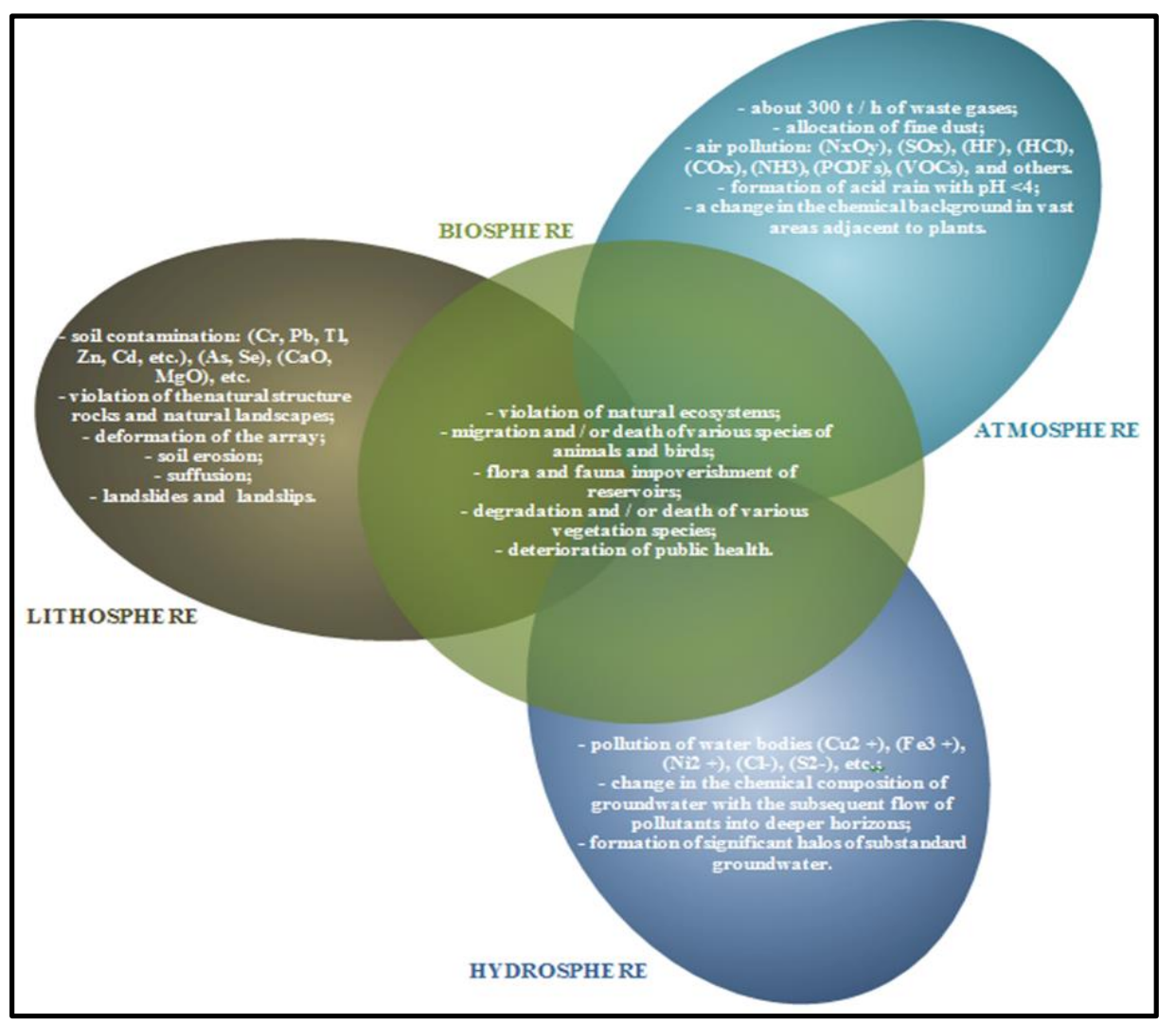

Fig. 4. Basic geoecological problems of cement production.

The formed negative forms of a relief negatively affect the state of the territory, dividing it and provoking further violation of a natural land relief. The geodynamic processes arising under the influence of gravitational forces, developing on slopes of various steepness and consisting in movement of various mass of rocks down on slopes - landslides, collapses and screes, were considered $[3,8,10]$.

During the complex development of gravity processes, a roughness is formed at the bottom of the quarries, between which surface and groundwater accumulates, which leads to local flooding and waterlogging. 
On the basis of route researches of territories of several quarries, which were held by the authors in the summers of 2016-2017, the schematic distribution map of superficial manifestations of dangerous exogenous geodynamic processes with the indication of degree of intensity of their passing was made (see fig. 5).

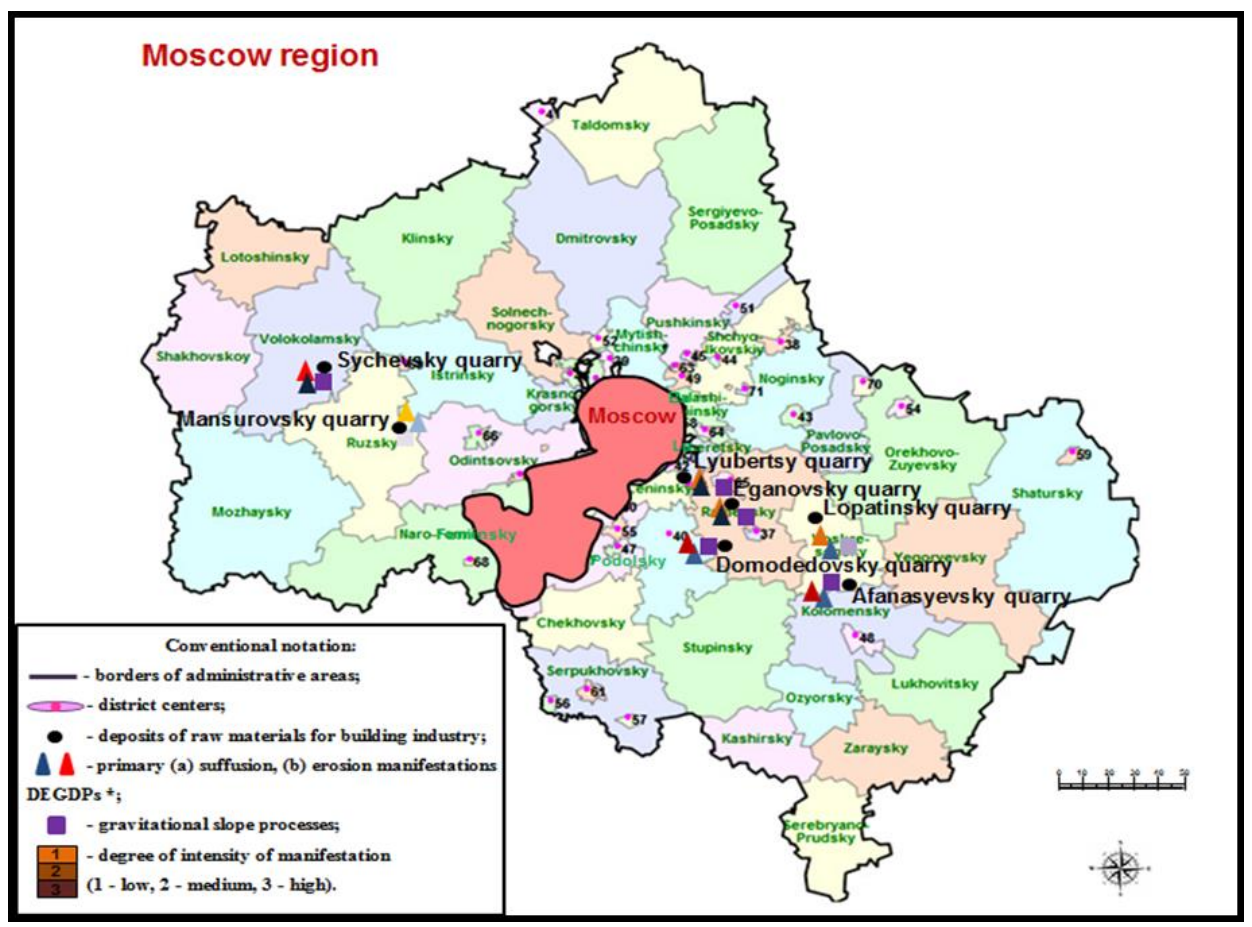

Fig. 5. Schematic map of the spread of surface manifestations of dangerous exogenous geodynamic processes in the quarries for the extraction of raw materials for building industry in the Moscow region.

Summary data on degree of intensity of superficial manifestations of dangerous exogenous geodynamic processes on the territory of quarries for extraction of non-metallic raw materials in Moscow region are presented in Table 1 and the Figure 5.

Table 1. The degree of intensity of surface manifestations of dangerous exogenous geodynamic processes in the quarries for the extraction of raw materials for building industry in the Moscow region.

\begin{tabular}{|l|c|c|c|}
\hline \multirow{2}{*}{$\begin{array}{c}\text { Name of quarry / degree of intensity of } \\
\text { manifestation dangerous exogenous } \\
\text { geodynamic processes }\end{array}$} & \multicolumn{2}{|c|}{ Manifestation } & \multirow{2}{*}{$\begin{array}{c}\text { Gravitational } \\
\text { slope processes }\end{array}$} \\
\cline { 3 - 4 } & Suffusion & Erosion & 3 \\
\hline Afanasyevsky quarry & 3 & 2 & 3 \\
\hline Domodedovsky quarry & 3 & 2 & 3 \\
\hline Eganovsky quarry & 2 & 3 & 2 \\
\hline Lopatinsky quarry & 2 & 2 & 3 \\
\hline Sychevsky quarry & 3 & 3 & 3 \\
\hline Mansurovsky quarry & 2 & 1 & 3 \\
\hline Lyubertsy quarries & 2 & 3 & 3 \\
\hline
\end{tabular}

Below are the criteria for assessing the degree of intensity of surface manifestations of dangerous exogenous geodynamic processes: 
3 - High degree characterized by a frequency of occurrence of 1 or more cases per 100 $\mathrm{m} 2$ of the quarry area. And the flow rate expressed through the volume of rock components removed from the array and the component for a given intensity is $11-20 \mathrm{~m} 3$ per year.

2 - Medium degree characterized by a frequency of occurrence of 1 or more cases per 500 $\mathrm{m} 2$ of the quarry area. And the flow rate expressed through the volume of rock components removed from the array and the component for a given intensity is 6-10 $\mathrm{m} 3$ per year.

1 - Low degree characterized by a frequency of occurrence of 1 or more cases per 1000 $\mathrm{m} 2$ of quarry area.

And the flow rate expressed through the volume of rock components removed from the array and the component for a given intensity is $1-5 \mathrm{~m} 3$ per year.

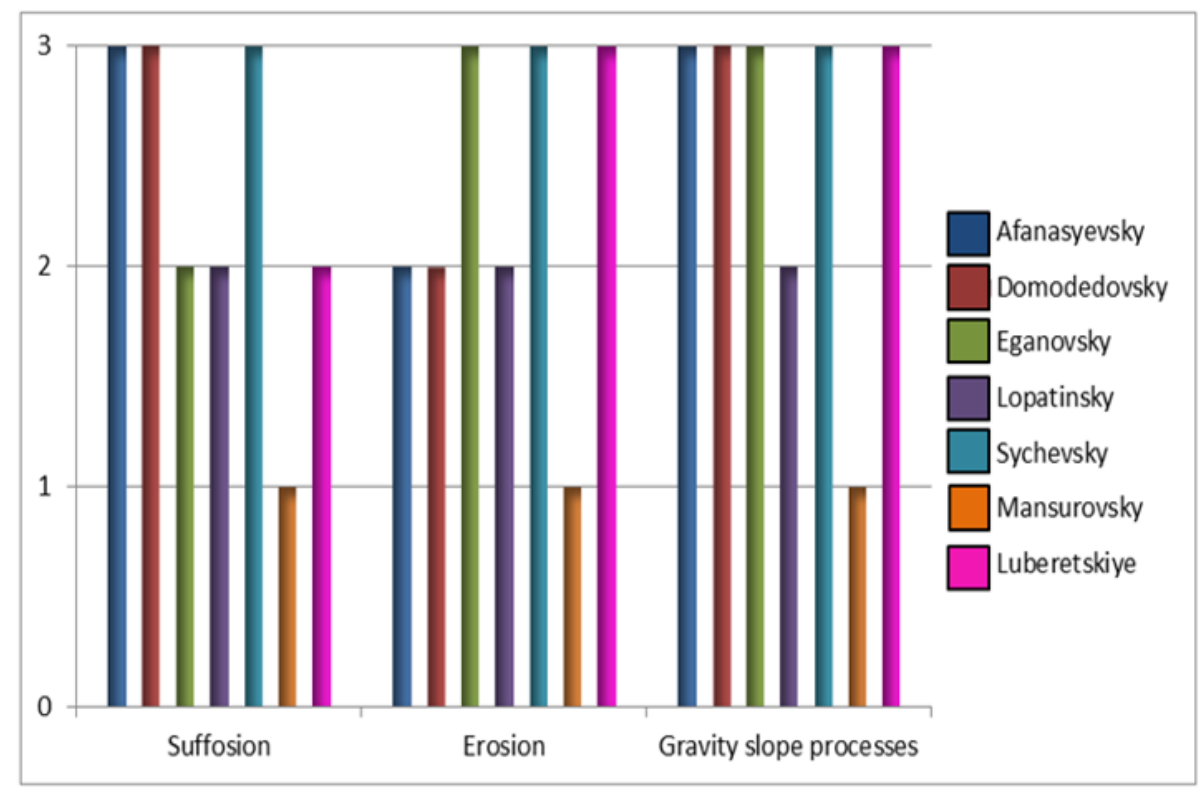

Fig. 6. The degree of intensity of surface manifestations of dangerous exogenous geodynamic processes in the quarries for the extraction of raw materials for building industry in the Moscow region.

According to the data presented, it can be concluded that in most areas of a developed raw material field, a high degree of development of dangerous exogenous geodynamic processes prevails. During the conducted research, the authors noted that the large part of raw fields was put into the operation more than 50 years ago, and the current state of many fields is unknown. Nowadays, it is possible to distinguish from them objects «safe» from the geoecological point of view and perspective for further development and the objects with the whole complex of geoecological problems [3, 4]. Besides, in most cases, the recultivation of the fulfilled territories of quarries is not carried out at all or carried out formally. As a result of the developed approach to the development of raw fields in Moscow region, we got to know that its geoecological state is extremely unsuccessful.

\section{Conclusions}

At the present stage of the development of society, the process of technogenesis leads to an irreversible, uncontrollable and hardly predictable change in natural complexes.

Constantly growing requirements of human society determine emergence of more and more effective technical means and technologies for development of raw fields. However, an 
increase in the rates of an expenditure and production of resources, which is inconsistent with the possibilities of self-restoration of Earth's geospheres, leads to violation of natural balance.

Geoecological consequences of the development of raw fields affect all geospheres of Earth. The replacement of a natural relief with technogenic one leads to the development of dangerous exogenous geodynamic processes, which is intensifying processes of deflation, aeration and leaching of massifs, and to considerable strengthening of migration of chemical elements due to excavation and movement of considerable volumes of breeds, the changes of the hydrological mode of territories and redistribution of ground streams of air.

On the territory of extraction, the intensity of the development of dangerous exogenous geodynamic processes caused by technogenic changes of a natural landscape is very high.

To monitor and prevent the deterioration of the geo-ecological situation in the quarry regions in time, comprehensive monitoring is required.

\section{References}

1. A.A. Lavrusevich, O.K. Vdovina, I.A. Lavrusevich, VI International Scientific Conference «Geoecological Problems of the Present», 18-22 (2014)

2. S.P. Gorshkov, Conceptual bases of geoecology (1998)

3. A.I. Podlesnykh, I.A. Lavrusevich, A.A. Lavrusevich, 19th Sergeevsky reading, 72-76 (2017)

4. A.I. Podlesnykh, I.A. Lavrusevich, Prospect and protection of mineral resources 6, 4651 (2016)

5. European Commission, Integrated Pollution Prevention and Control (IPPC), Reference Document on Best Available Techniques (BREF) in the Cement and Lime Manufacturing Industries, http://eippcb.jrc.es (2007)

6. Z.T. Fokina, A.I. Podlesnykh, Bulletin MGSU 11, 130-141 (2015)

7. M.N. Baranova, N.G. Chumachenko, V.V. Tyurnikov, Bulletin SGASU, Urbanism and architecture 1, 80-85 (2014)

8. A.A. Lavrusevich, F.F. Bruykhan, I.A. Lavrusevich, V.P. Khomenko, Industrial and Civil construction 11, 15-18 (2014)

9. V.P. Khomenko, Laws and predictions of the suffusion processes (2003)

10. G.K. Bondarik, V.V. Pendin, L.A. Yarg, Engineering geodynamics (2015) 